Journal of Cleaner Production, Volume 248, March 2020, Article number 119246

DOI: $10.1016 /$ j.jclepro.2019.119246

\title{
Integrating biomass into energy supply chain networks
}

Oluwatosin C. Murele ${ }^{a}$, Nur I. Zulkafli ${ }^{b}$, Giorgos Kopanos ${ }^{c}$, Phil Hart $^{a}$, Dawid P. Hanak ${ }^{a *}$

${ }^{\mathrm{a}}$ Energy and Power, School of Water, Energy and Environment, Cranfield University, Bedford, Bedfordshire, MK43 0AL, United Kingdom.

${ }^{b}$ Centre of Advanced Research on Energy, Faculty of Mechanical Engineering, Universiti Teknikal Malaysia Melaka, Durian Tunggal, Melaka 76100, Malaysia.

${ }^{c}$ Flexciton Ltd, London EC1Y 2AL, United Kingdom.

Corresponding author: *Dawid P. Hanak, d.p.hanak@cranfield.ac.uk 


\begin{abstract}
During a period of transition towards decarbonised energy networks, maintaining a reliable and secure energy supply whilst increasing efficiency and reducing cost will be key aims for all energy supply chain (ESC) networks. Renewable energy sources, such as biomass, will play an important role in future ESC's as climate change mitigation becomes an increasingly important priority. This paper seeks to address these requirements by presenting an optimization model for the design and planning of biomass integration into the ESC networks. A supply chain model was derived and the governing equations were solved using the General Algebraic Modelling System software (GAMS) to achieve an optimal solution. The results of the study indicate that a reduction in the emissions cost of up to $4.32 \%$ is achievable on integration of 5-8\% of biomass into the ESC network. However, a $4.57 \%$ increase in the total cost of the ESC network was recorded at the biomass fraction in the mixed fuel of $7.9 \%$, with the fixed assets cost having the largest impact on the total cost of the ESC network. It has been shown that the cost increment in the assets and operational costs of a biomass and coal co-fired combined heat and power plant can be offset by the cost reductions obtained from reduced carbon dioxide emissions. Economic arguments for dual-fuel plants, therefore, require the introduction of effective carbon pricing legislation. It is concluded that such policy implementations can be effective at mitigating the effects of climate change and would assist in achieving a global carbon neutral economy.
\end{abstract}

KEYWORDS: Renewable energy sources, dual fuel plants, fossil fuel, optimization tool, carbon pricing legislation, biomass co-firing 


\section{Introduction}

Renewable energy is attributed to sources of energy that are not depleted by their use, such as wind, solar, hydro, geothermal and bioenergy. Their integration into energy supply chain (ESC) networks, aimed at a gradual replacement of conventional fossil fuels for electricity generation, district heating, transportation and off-grid/rural energy services (REN21, 2018) will play a significant role in achieving the global emission reduction targets. Importantly, $\mathrm{CO}_{2}$ emissions from energy-related processes and operations increased by $1.7 \%$ between 2017 and 2018 , reaching $33.1 \mathrm{GtCO}_{2}$ in 2018 (IEA, 2018). This increase resulted mostly from the combustion of fossil fuels in the power sector which constituted almost two-thirds $\left(\sim 350 \mathrm{MtCO}_{2}\right)$ of the $\mathrm{CO}_{2}$ emissions

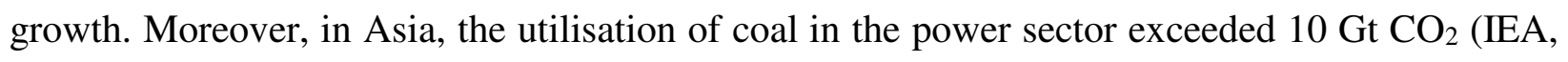
2018), which accounts for $30.2 \%$ of the global energy-related $\mathrm{CO}_{2}$ emissions. As a result, it is becoming even more challenging to meet the emission reduction targets set out in the Paris Agreement that are a legally binding set of environmental targets. These cap global warming to a value less than $2^{\circ} \mathrm{C}$ greater than that of pre-industrial levels, with a desire for its reduction to $1.5^{\circ}$ (EC, 2015). Nevertheless, it is essential to note that the growth in $\mathrm{CO}_{2}$ emissions was $25 \%$ lower than that of the energy demand (IEA, 2018), mostly due to the deployment of low-carbon technologies such as renewable energy sources and nuclear, and energy efficiency gains. 215 $\mathrm{MtCO}_{2}$ emissions were avoided as a result of switching to renewables in the power sector (IEA, 2018). Although this trend is promising, the rate at which low-carbon technologies are implemented in the ESC networks may not be sufficient to meet the desired emission reduction targets. Therefore, pathways for their cost-effective implementation need to be derived.

Regardless of these ambitious environmental targets, fossil fuels (coal, oil, natural gas) still play an essential role in the current energy systems (Ritchie and Roser, 2018). The ESC networks based 
on fossil fuels for electricity generation consist of (Energy Exchange, 2018):

- generation points involving energy material resource and its costs;

- transformers used for the conversion of low voltage electricity to high voltage electricity that are necessary for efficient transportation;

- transmission lines with associated network costs;

- substation transformers that convert high voltage electricity to low voltage electricity for distribution;

- distribution lines that also contribute to the network costs; and

- retail services that deal with the sales of energy products to customers.

Importantly, the use of fossil fuels results in the emission of carbon dioxide $\left(\mathrm{CO}_{2}\right)$, which is one of the main greenhouse gases leading to global warming. These non-renewable resources have limited availability that influences the security of energy supply in the long term. Ultimately, this calls for an immediate action directed at balancing the role of energy in technological, social, economic and environmental development towards a transition to low-carbon energy sources (Ritchie and Roser, 2018). Although fossil fuels play a significant role in the current global energy portfolio, which is characterised with high level of greenhouse gas emissions, their limited availability and links to geopolitical uncertainties pose a threat to the global energy security. Therefore, innovations aimed at integrating renewable energy sources into ESC networks need to be deployed at a scale in a cost-effective manner. The formulation of efficient optimisation models to support the design of effective ESC networks is critical to meeting the greenhouse gas emission reduction targets.

In order to achieve a substantial shift towards renewable energy sources, the integration of biomass into the existing ESC networks can be considered (Duarte et al., 2014). Biomass, being a renewable 
energy material resource, has a potential to contribute towards a reduction of the dependency on fossil fuels. The key advantage of biomass is the fact that it is considered as a versatile energy source as it can be converted into heat, electricity and fuels. Furthermore, it is also one of the renewable energy sources that is capable of generating energy on demand (Rentizelas et al. 2009); hence, it can also be considered as a non-intermittent energy source, as this attribute of biomass can be a solution to the variability of other renewable energy sources, such as wind and solar.

With continuous demand for energy at an affordable cost and reliable supply (Sharma et al., 2013), all available resources should be harnessed efficiently and integrated into an existing ESC network. This links to achieving a well-structured supply chain which is characterised by an optimal energy supply pathway, obtained at a minimum possible cost. Such an optimisation problem can be represented using the state-task network (STN) approach to supply chains.

Biomass is known to be a low-density material that could be lost during transportation from its original place of harvest or collection to an intermediate point of conversion. This implies the need for an improved and effective supply chain (Rentizelas et al., 2009). However, for biomass integration in an existing ESC network to be worthwhile, the energy materials in use should be sourced locally. This is because local sourcing of biomass materials can result in shorter supply chains with higher predictability of delivery times and at reduced costs and greenhouse gas emissions. The biomass supply chain (BSC) is characterised with a range of uncertainties, such as weather, seasonality, physical and chemical characteristics, biomass suppliers and their willingness to grow biomass crops, transportation and distribution infrastructure, supplier contracts and government policies (Sharma et al., 2013). Moreover, different types of biomass resources, such as energy crops, agricultural residues, municipal solid waste and forest residue make use of customized equipment for their collection, handling and storage, further increasing 
the level of complexity of the supply chain, which invariably is a determining factor in the investments and operational costs. This also affects the design and planning of the supply chain networks (Rentizelas et al. 2009). Therefore, to design an efficient BSC/ESC, the design in combination with adequate planning must be implemented with the material resources undergoing some conversion processes before the end products can be used effectively by consumers.

According to Pérez-Fortes et al. (2014), decision making models that can accommodate multiple stakeholders and activities in the development of the supply chain should be considered. The process involved in the decision making fall under three perspectives: strategic, tactical and operational. Strategic decisions are long-term decisions that could be revised after five or more years in accordance to the dictates of the business entity. These include decisions such as the establishment of coal-fired power plants as well as co-fired combined heat and power (CHP) plants. Tactical decisions are made on a medium-term basis, with a span ranging between six months and one year. These usually focus on inventory planning, logistical needs and distribution networks. Finally, operational decisions are short-term decisions made on a daily or weekly basis (Awudu and Zhang, 2012). However, due to significant differences in the operating systems of the BSC networks and, to a large extent, number of decisions that need to be made in their operational design and planning, these networks are complex (Miret et al., 2016). This makes it challenging to find the right optimisation methods and arrive at optimal solutions in real time.

To solve the abovementioned challenges, activities in the BSC/ESC networks are represented by mathematical models. Several different optimisation-based approaches have been applied by considering a single objective function and the solution focused on specific supply chains having biomass as their energy resource. These networks were developed to increase productivity and eliminate current inefficiencies experienced in order to satisfy the future needs of growing 
population (Banasik et al., 2018). Yue et al. (2016) developed a framework that combined a life cycle assessment and multi-objective optimization for a comprehensive life cycle optimization of a bioethanol supply chain. This framework was based on mixed-integer linear programming (MILP) and evaluated different kinds of feedstocks from both environmental impact and economic performance standpoints. Eksioglu and Hadi (2015) developed a nonlinear mixed-integer programming (NMIP) model that represented the impact of costs related to logistics, capital investments, the efficiency of the power plant, credit obtained on tax as well as reductions in emissions, on the overall ESC cost. The objective of their work was to maximise the profit that invariably corresponds to a reduction in the overall cost of the ESC. Eksioglu et al. (2016) presented a NMIP model that combines decisions related to production and transportation at power plants. Their model was based on a Lagrangean relaxation for efficient solution of real-life scenarios considered in their study. It captured losses in efficiency as a result of using biomass, an increase in the investment costs associated with biomass co-firing and savings accrued as a result of production tax credit. Roni et al. (2014) presented a supply chain model based on MILP that follows a hub-and-spoke network design for biomass delivery on a long-haul basis. The model was solved using the Benders decomposition algorithm to minimize the biomass transportation cost based on its volume and distance from a coal-fired power plant. The optimization problem presented by Han and Murphy (2012) was based on truck scheduling for the transportation of forest biomass from harvesting locations and sawmills to heat production plants. Their model used a heuristic algorithm, so-called simulated annealing, to minimize the transportation cost and total travel time across the supply chain.

The review of the approaches used to minimize the total cost of integrating biomass into ESC indicates that most of these studies were based on the multi-period super-structural models, 
whereas the STN approach has not been yet considered. The main benefit of using STN approach is that it considers simultaneous management of both material and energy flows across the ESC embedded within a common optimization framework. This offers a reduced computational time to arrive at the optimum solution, without compromising its optimality. Therefore, this study aims to formulate an efficient optimisation model and to recommend an optimal pathway for biomass integration in the ESC. It focuses on determining the most cost-effective biomass fraction in the mixed solid fuel that will result in an appreciable reduction in $\mathrm{CO}_{2}$ emissions when integrated into the design and planning of existing ESC networks. The proposed optimisation model is developed in General Algebraic Modelling System (GAMS) and employs the STN approach to model, and solving for optimality of, the considered ESC network. The optimisation problem has been defined with considerations given to all constraints governing the design of the supply chain, alongside capacity expansions of the installed technologies considering uncertainties in the values of some parameters, such as varying supply of energy resulting from the demand variations, which must be met.

\section{Methodology}

This study focuses on the $\mathrm{CO}_{2}$ emissions mitigation potential of co-firing biomass with coal using a power plant model represented as the STN. Figure 3 displays a schematic representation of the plant layout, which represents a typical biomass and coal co-fired plant. The plant consists of eight states $(s 1-s 8)$, which comprises of two raw materials states, $(s 1, s 8)$, three energy material resources states, $(s 2, s 3, s 6)$, two energy form states $(s 5, s 7)$ and one unwanted substance state $(s 4)$. Seven tasks ( $p 1-p 7)$, which are a combination of exploitation tasks $(p 1, p 7)$, conversion tasks $(p 2, p 4, p 5)$ and transfer tasks $(p 3, p 6)$ and eleven technologies (q1-q11), representing, exploitation technologies $(q 1, q 10)$, conversion technologies $(q 2, q 5, q 6, q 7, q 8)$, transfer technologies $(q 3, q 4$, q9) and storage technology (q11) are included. 
Coal and biomass (wood chips) material resources are exploited locally through coal mining and biomass harvesting from trees. The mixed solid fuel is passed through a mechanical conversion process such as milling in order to reduce particle size and ensure uniformity, resulting in an increased fuel surface area for co-firing operation. The biomass and coal mixture is passed through a conveyor and subsequently undergoes pneumatic transfer for onward delivery to either the cocombustion chamber or the co-gasification chamber. For the cost optimisation process, thermochemical conversion in the co-combustion chamber is considered as it is less expensive than the gasification option. Co-combustion, which is also more mature technology, negates the need for the pressure vessels required in the gasification option, improving overall process reliability.

The result of the co-combustion of coal and biomass in the combustion chamber produces secondary energy material resources, which could be unreacted coal and biomass ( $s 3$ ), energy form state (s5) in the form of heat, as well as unwanted substances (s4) which could be in form of $\mathrm{CO}_{2}$, $\mathrm{NO}_{\mathrm{x}}, \mathrm{SO}_{2}$ in addition to varying and naturally occurring radioactive materials. The produced heat of combustion is used to convert water into steam, which drives the turbine to produce electricity in the generator. The produced electrical power and heat $(s 7)$, which are energy form states, are obtained from the turbine. Their production rates depend on the amount of steam produced in the steam generator. Electricity is subsequently transferred to various points of usage, while heat can be used in process or district heating.

The unique characteristic of the STN approach is that it consists of two types of nodes. The state nodes denote the feedstock, intermediate and final products that are represented by circles in Figure 1. The processing operations nodes denote processes that transform energy materials from one or more input/initial states to one or more output/final states and are represented by rectangles in 
Figure 1. As such, process operations are distinguished from the resources that are used in performing them.

Furthermore, the costs considered in the ESC networks refer to absolute costs and not unit costs. However, in this particular case study, time value of money (net present value analysis) was not a considered objective function, and as such, the cost results are not discounted.

In view of the aforementioned, the equations are formulated using the MILP method and same implemented and solved using the CPLEX 12 optimization solver of the GAMS software, on an Intel® Core $^{\mathrm{TM}}$ i5-6200U CPU @ $2.40 \mathrm{GHz}$ system with a zero optimality gap and under a negligible computational time. The limitations of the considered approach include no consideration of the solid fuel characteristics, such as particle shape, size distribution, composition, that would affect the quantity of biomass that could be co-fired with the coal. However, this work focused on the optimisation of the ESC from the technology cost and $\mathrm{CO}_{2}$ emissions perspective to determine optimum fraction of biomass technologies in the ESC. Moreover, seasonality of biomass supply and technical challenges of its implementation in co-fired systems, such as slagging, fouling and corrosion, were not considered (IEA, 2013). Finally, the model presented in this work follows the deterministic approach of modelling the ESC networks.

\subsection{Modelling Approach}

The model used in this work considers processes involved in the integration of biomass into an existing coal-based ESC network leading to complexity of the ESC. In view of this development, the modelling approach of energy STN formulation for supply chains introduced by Kondili et al. (1993) and applied by Zulkafli \& Kopanos. (2018) has been adapted.

The formulation follows a multi-period timespan (20 equally distributed yearly time horizons), with the advantage of representing the problem as a STN model to allow for its extension to 
industrial supply chains with other systems. Long time horizons for decision making have been considered as this is usually necessary for design problems due to strategic decisions that need to be made. Moreover, the annual time periods considered can also be represented as monthly time periods, allowing a more flexible ESC networks.

In the approach, material resources, individual tasks and useful products states are represented as separate nodes of the ESC network. In general, the E-STN comprise of two types of nodes: the state nodes denoted by circles which represent the feeds, both intermediate and final products; and the task nodes denoted by rectangles, representing processing operations that transform materials from one or more input states to one or more output states as shown in Figure 1. These states and tasks nodes are linked by arcs, representing the flow of materials from one point to another.

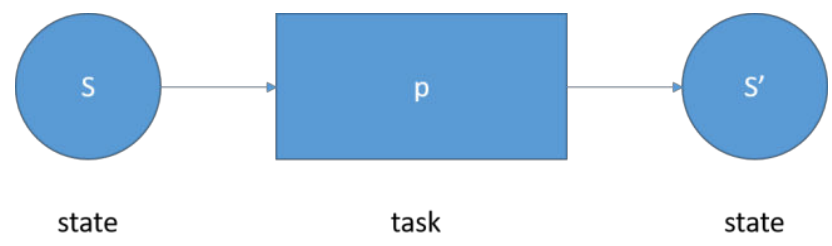

Figure 1: General representation of state-task network

For some of the constraints, such as capacity levels of technologies, the modelling framework considers bounds to account for the economies of scale on the lower side and biodiversity on the upper side (Babazadeh, 2016).

Establishment of technologies and bounds on expansion capacities are considered under the design constraints, while the availability of raw materials states and states connection with their balances are considered under the planning constraints. The link between design and planning are connected by constraints which provide bounds (upper and lower) on the level of operation on the amount of states converted, pre-processed or transferred by associated tasks with the use of applicable technology from one region to another in the time period under consideration. 


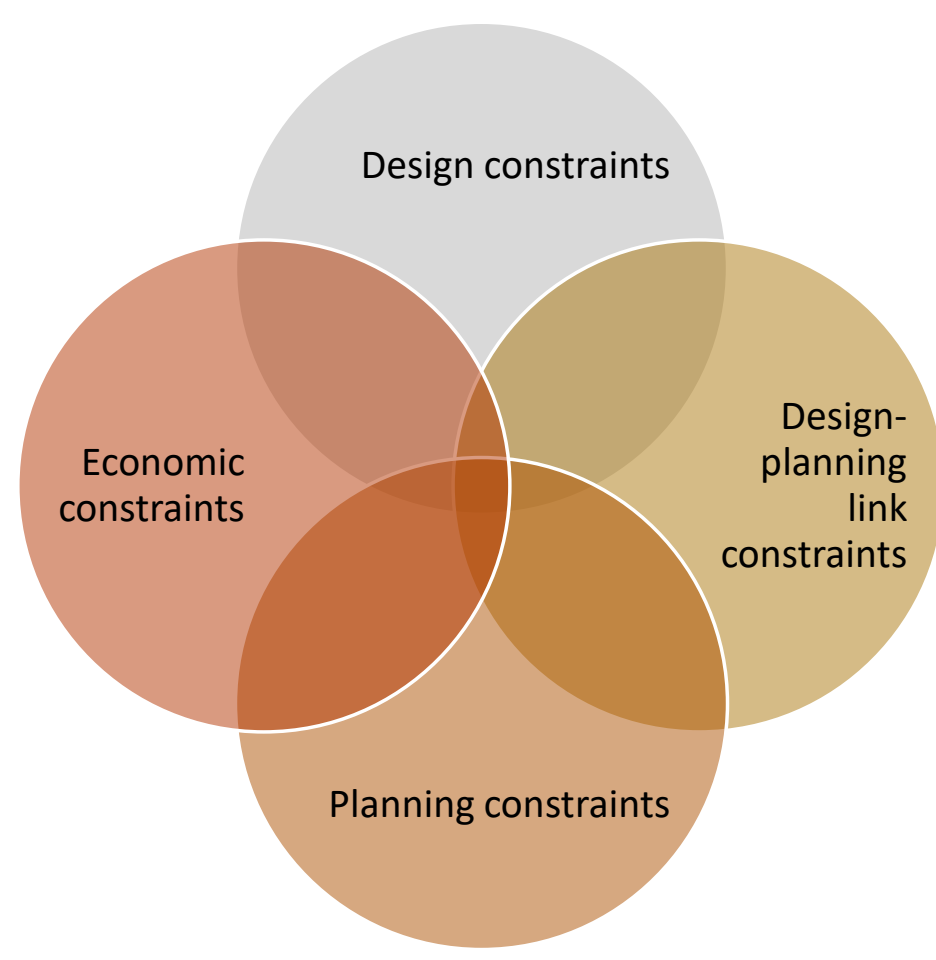

Figure 2: Major constraints for the proposed approach

The economics constraints relate to the overall costs considered in the ESC network. It consists of the fixed assets costs for conversion, local/biomass exploitation and storage technologies that relate to the investment made in the establishment and expansion of technologies. Moreover, the total investment for establishing a transfer network between the two regions is represented by the fixed transfer costs. The fixed operating costs are the cost associated with maintenance and administration of the co-fired CHP plant on a day-to-day basis.

\subsection{Optimisation Framework}

2.2.1 Constraints for the design: Technologies establishment and corresponding expansions for installed capacities

The following binary variables are used in the modelling of the establishment operations of the ESC networks: 
$V_{(r, q, t)}=1$, if local/biomass exploitation, pre-processing and conversion technologies are established for the first time in region $r$ at time period $t$, zero if otherwise.

$V_{(r, s, q, t)}^{G} \quad=1$, if storage technology $q$ for state $s$ is established for the first time in region $r$ at time period $t$, zero if otherwise.

$Z_{(r, q, t)}=1$, if capacity of local/biomass exploitation, pre-processing and conversion technology q begins installing in region $r$ at time period $t$, zero if otherwise.

$Z_{(r, s, q, t)}^{G}=1$, if capacity of storage technology q for state $s$ begins installing in region $r$ in time period $t$, zero if otherwise.

$Z_{\left(r, r^{\prime}, q, t\right)}^{T R}=1$, if capacity of transfer technology $q$ starts installing in region $r$ in time period $t$, zero if otherwise.

Equation (1) shows the initial installation of local/biomass exploitation or conversion $\left(V_{(r, q, t)}\right)$ and storage technology, $\left(V_{(r, s, q, t)}^{G}\right)$, in region $r$ and at time period $t$, with the constraint showing that it can happen at most once in the internal region, while Equations (2) and (3) depict the link in binary variables for local/biomass exploitation, conversion and storage technologies. It is important to note that the establishment of these technologies cannot exceed the corresponding capacities, as shown in Equations (1-3).

$$
\begin{gathered}
\sum_{t \in T} V_{(r, q, t)} \leq 1 \quad \forall r \in R^{i n}, q \in Q_{r}^{P R C} \\
\sum_{t \in T} V_{(r, s, q, t)}^{G} \leq 1 \quad \forall r \in R^{i n}, s \in S, q \in Q_{(s, r)}^{G} \\
V_{(r, q, t)} \leq Z_{(r, q, t)} \quad \forall r \in R^{i n}, q \in Q_{r}^{P R C}, t \in T \\
V_{(r, s, q, t)}^{G} \leq Z_{(r, s, q, t)}^{G} \quad \forall r \in R^{i n}, s \in S, q \in Q_{(s, r)}^{G}, t \in T \\
V_{(r, q, t)} \geq Z_{(r, q, t)}-\sum_{t^{\prime}<t} V_{\left(r, q, t^{\prime}\right)} \quad \forall r \in R^{i n}, q \in Q_{r}^{P R C}, t \in T \\
V_{(r, s, q, t)}^{G} \geq Z_{(r, s, q, t)}^{G}-\sum_{t^{\prime}<t} V_{\left(r, s, q, t^{\prime}\right)} \quad \forall r \in R^{i n}, s \in S_{r}^{G}, q \in Q_{(s, r)}^{G}, t \in T
\end{gathered}
$$

\subsubsection{Overall capacity for technologies establishment and expansions}


The total installed capacity for each region and time period, for conversion or biomass/local exploitation technology, $\left(C_{(r, q, t)}\right)$, storage technology, $\left(C_{(r, s, q, t)}^{G}\right)$ and transfer technology, $C_{\left(r, r^{\prime}, q, t\right)}^{T R}$ with their expansions are represented by Equations (4), (5) and (6), respectively. The initially established capacities for exploitation/conversion, storage and transfer technologies are represented respectively by the parameters, $\varphi, \varphi^{G}, \varphi^{T R}$, while $\boldsymbol{E}, E^{G}, E^{T R}$ denote the expansions in capacities happening at every applicable time period and region.

As shown in Equation (6), there is no existing transfer station representing the total installed capacity for transfer technology for each region and time period in addition to their expansions $C_{\left(r, r^{\prime}, q, t-1\right)}^{T R}$ at time $\mathrm{t}=1$. As it is a first time period $(\mathrm{t}=1)$, it is assumed that the production of transferrable states must first occur in this time period $(\mathrm{t}=1)$ before the transfer technologies can be established at the time periods $t>1$. It is assumed that for an additional technology to be established, a capacity expansion on the applicable technologies must occur at the same time with establishing the technologies.

$$
\begin{aligned}
& C_{(r, q, t)}=\varphi_{(r, q)}+C_{(r, q, t-1)}+E_{(r, q, t)} \forall r \in R^{i n}, q \in Q_{r}^{C P R}{ }_{(s, r)}, t \in T: t=1 \\
& C_{(r, q, t)}=C_{(r, q, t-1)}+E_{(r, q, t)} \forall r \in R^{i n}, q \in Q_{r}^{C P R}, T: t>1 \\
& C_{(r, \mathrm{~s}, q, t)}^{G}=\varphi_{(r, \mathrm{~s}, q)}^{G}+C_{(r, \mathrm{~s}, q, t-1)}^{G}+E_{(r, \mathrm{~s}, q, t)}^{G} \forall r \in R^{i n}, \mathrm{~s} \in \mathrm{S}_{r}{ }^{G} \quad q \in Q_{(s, r)}^{G}, t \in T: t=1 \\
& C_{(r, \mathrm{~s}, q, t)}^{G}=C_{(r, \mathrm{~s}, q, t-1)}^{G}+E_{(r, \mathrm{~s}, q, t)}^{G} \forall r \in R^{i n}, \mathrm{~s} \in \mathrm{S}_{r}^{G}, q \in Q_{(s, r)}^{G}, T: t>1 \\
& C_{\left(r, r^{\prime}, q, t\right)}^{T R}=\varphi_{\left(r, r^{\prime}, j\right)}^{T R}+E_{\left(r, r^{\prime}, q, t\right)}^{T R} \quad \forall r \in R^{i n}, r^{\prime} \in R_{r^{\prime}}^{T R}, q \in Q_{\left(r, r^{\prime}\right)}^{T R}, t \in T: t=1 \\
& C_{\left(r, r^{\prime}, q, t\right)}^{T R}=C_{\left(r, r^{\prime}, q, t-1\right)}^{T R}+E_{\left(r, r^{\prime}, q, t\right)}^{T R} \quad \forall r \in R^{i n}, r^{\prime} \in R_{r^{\prime}}^{T R}, q \in Q_{\left(r, r^{\prime}\right)}^{T R}, t \in T: t>1
\end{aligned}
$$

Equations (7) and (8) are used to determine the gamma ( $\gamma$ ) parameters that represent the bounds (upper and lower) on allowable expansion levels of associated technologies of the supply chain. Also, parameters $\mu_{(r, q, t)}$ and $\mu_{\left(r, r^{\prime}, q, t\right)}$ are the time for installation of a technology's expansion in 
capacity after it is available and time for installation for a transfer technology that connects the two regions for an implementation start in the period under consideration.

$$
\begin{array}{cc}
\gamma_{(\mathrm{r}, \mathrm{q}, t)}^{\min } Z_{\left(\mathrm{r}, \mathrm{q}, t-\mu_{(\mathrm{r}, \mathrm{q}, t)}\right.} \leq E_{(\mathrm{r}, \mathrm{q}, t)} \leq \gamma_{(\mathrm{r}, \mathrm{q}, t)}^{\max } Z_{\left(\mathrm{r}, \mathrm{q}, t-\mu_{(\mathrm{r}, t, t)}\right)} & \forall r \in R^{i n}, \mathrm{q} \in Q_{r}^{C P R}, t \in T \\
\gamma_{(z, j, t)}^{\min } Z_{\left(\mathrm{r}, s, \mathrm{q}, t-\mu_{(\mathrm{r}, \mathrm{q}, t)}\right)}^{G} \leq E_{(\mathrm{r}, s, \mathrm{q}, t)}^{G} \leq \gamma_{(\mathrm{r}, \mathrm{q}, t)}^{\max } Z_{\left(\mathrm{r}, s, \mathrm{q}, t-\mu_{(\mathrm{r}, \mathrm{q}, t)}\right)}^{G} & \forall r \in R^{i n}, s \in S_{r}^{G}, \mathrm{q} \in Q_{(s, \mathrm{r})}^{G}, t \in T \\
\gamma_{\left(\mathrm{r}, \mathrm{r}^{\prime}, t\right)}^{\mathrm{TR}, \min } Z_{\left(\mathrm{r}, \mathrm{r}^{\prime}, \mathrm{q}, t-\mu_{(\mathrm{r}, \mathrm{r}, \mathrm{q}, t)}^{T R}\right)}^{T R} \leq E_{\left(\mathrm{r}, \mathrm{r}^{\prime}, \mathrm{q}, t\right)}^{T R} \leq \gamma_{\left(\mathrm{r}, \mathrm{r}^{\prime}, t\right)}^{\mathrm{TR}, \max } Z_{\left(\mathrm{r}, \mathrm{r}^{\prime}, j, t, \mu_{\left(\mathrm{r}, r^{\prime}, t, t\right)}^{T R}\right)}^{T R} & \forall r \in R^{i n}, \mathrm{r}^{\prime} \in R_{r^{\prime}}^{T R}, \mathrm{q} \in Q_{\left(\mathrm{r}, \mathrm{r}^{\prime}\right)}^{T R}, t \in T
\end{array}
$$

\subsubsection{Availability for raw materials states}

The raw materials considered in this work is wood chips, which is a type of biomass and a goodquality fuel that requires a simplified harvesting and drying (Warren et al., 1995) and a nonintermittent renewable energy source, in addition to coal, both are solid fuels. The capacity of inventory for the selected technology is denoted by Equation (9), which indicates that the amount of renewable state consumed by task $p \in P$ brought about by biomass/local exploitation technologies $q \in Q,\left(M_{(r, r, p, q, t)}\right)$ in addition to those transferred to other regions, $\left(M_{\left(r, r^{\prime}, p, q, t\right)}\right)$ cannot exceed the maximum amount of the state that is available originally at the source region, $\left(\omega_{(r, s, t)}\right)$.

$$
\sum_{p \in P_{s}^{R M}} \sum_{q \in\left(Q_{r}^{E} \cap Q p\right)} M_{(r, r, p, q, t)}+\sum_{p \in P_{s}^{T}} \sum_{q \in\left(Q_{(r, r)}^{T} \cap Q_{p}\right)} \sum_{r^{\prime} \in R_{r^{\prime}}^{T}} M_{\left(r, r^{\prime}, p, q, t\right)} \leq \omega_{(r, s, t)} \quad \forall r \in R, s \in S_{r}^{R M}: s \notin S^{N R}, t \in T
$$

\subsubsection{Connection and balance for applicable states}

Equation (10) shows the link between connection and balance in each of the regions at the end of each time period. This equation shows that the level of inventory of storable states $s \in S_{r}{ }^{G}$ at the end of each time period and region depend on the following: 
(i) the inventory at the end of the time period before the one being considered, given by $G_{(r, s, t-1)}$ with consideration given to associated deterioration, $\eta_{(r, s, t)}$. In the case of biomass, if the moisture content is not properly reduced before storage, fungi, which can destroy wood by metabolizing cellulose, hemicellulose and lignin are able to cause material losses;

(ii) the applicable demand for the state;

(iii) no sales or unmet demands;

(iv) quantity of states disposed;

(v) produced amount from local/biomass exploitation task;

(vi) quantity of transferred states either through the inlet or outlet processes; and

(vii) tasks produced, $P \in P_{s}^{+}$or consumed $P \in P_{s}^{-}$by other tasks.

For states that cannot be stored, $s \notin S_{r}{ }^{G}$ all the criteria listed above apply except from the first one.

$$
\begin{aligned}
& G_{(r, s, t)}=\left(1-\eta_{(r, s, t)}\right) G_{(r, s, t-1)}-\zeta_{(r, s, t)}+N_{(r, s, t)}-D_{(r, s, t)}+\overbrace{\sum_{p \in P_{s}^{R M}} \sum_{q \in\left(Q_{r}^{E} \cap Q p\right)} M_{(r, r, p, q, t)}} \\
& +\overbrace{\sum_{r^{\prime} \in R_{r}^{T R}} \sum_{p \in P_{s}^{T R}} \sum_{q \in\left(Q_{\left(r^{T}, r\right)}^{T R} \cap Q p\right)} \kappa_{(s, p, q)}^{+} M_{\left(r^{\prime}, r, p, q, t\right)}}-\overbrace{\sum_{r^{\prime} \in R_{r}^{T R}} \sum_{p \in P_{s}^{T R}} \sum_{q \in\left(Q_{(r, r)}^{T R} \cap Q p\right)} \kappa_{(s, p, q)}^{-} M_{\left(r, r^{\prime}, p, q, t\right)}} \\
& +\overbrace{\sum_{p \in P_{s}^{+}} \sum_{q \in\left(Q_{r}^{C} \cap Q p\right)} \kappa_{(s, p, q)}^{+} M_{(r, r, p, q, t)}}-\overbrace{\sum_{p \in P_{s}^{-}} \sum_{q \in\left(Q_{r}^{C} \cap Q p\right)} \kappa_{(s, p, q)}^{-} M_{(r, r, p, q, t)}} \forall r \in R, s \in S_{r}, t \in T \\
& G_{(r, s, t=0)}=G_{(r, s)}^{0} \quad \forall r \in R, s \in S_{r}^{G} \\
& G_{(r, s, t)}=0 \quad \forall r \in R, s \notin S_{r}^{G}, t \in T \\
& D_{(r, s, t)}=0 \quad \forall r \in R, s \notin S_{r}^{D}, t \in T
\end{aligned}
$$

Biomass inventory, $G_{(r, s)}^{0}$ considered as the initially available inventory of state $s$ in region $r$ (at the initial time period, $t=0$ ) and has been set to 10,000 units. It is worth noting that the model 
presented does not depend on units used as long as the units are consistent. The main focus of this study is to show new models that can solve the kind of case study presented.

\subsubsection{Objective function}

The objective function is set to achieve minimisation of overall costs that comprise the fixed assets costs for technologies (pre-processing and conversion, biomass/local exploitation and storage) that have been installed, fixed assets cost for transfer technology, and the fixed and variable operating costs. The variable cost is made up of cost of production, inventory cost, transfer cost and raw materials cost.

$$
\min \sum\left(F A C_{t}+F A C_{t}^{T R}+F O C_{t}+V O C_{t}\right)
$$

In Equation (11), $F A C_{t}$ is the fixed assets costs associated with biomass/local exploitation, conversion, pre-processing and storage technologies in time period $t, F A C_{t}^{T R}$ is that of the transfer technologies also in time period $\mathrm{t}, F O C_{t}$ is the fixed operating costs in time period $\mathrm{t}$, while, $V O C_{t}$ is the variable operating cost in time period $t$ and are shown by Equations (12-15), respectively.

$$
\begin{gathered}
F A C_{t}=\sum_{r \in R^{i n}} \sum_{q \in Q_{r}^{P R C}}\left(\varepsilon_{(r, q, t)}^{0} V_{(r, q, t)}+\varepsilon_{(r, q, t)} E_{(r, q, t)}\right)+\sum_{r \in R^{i n}} \sum_{s \in S_{r}^{G}} \sum_{q \in Q_{(s, r)}^{G}}\left(\varepsilon_{(r, q, t)}^{0} V_{(r, s, q, t)}^{G}+\varepsilon_{(r, q, t)} E_{(r, s, q, t)}^{G}\right) \quad \forall t \in T \\
F A C_{t}^{T R}=\sum_{r \in R^{i n}} \sum_{r^{\prime} \in R_{r^{T}}^{T R}} \sum_{q \in Q_{\left(r^{\prime}, r\right)}^{T R}}\left(\varepsilon_{\left(r, r^{\prime}, t\right)}^{T R 0} Z_{\left(r, r^{\prime}, q, t\right)}^{T R}+\varepsilon_{\left(r, r^{\prime}, q, t\right)}^{T R} E_{\left(r, r^{\prime}, q, t\right)}^{T R}\right) \quad \forall t \in T \\
F O C_{t}=\sum_{r \in R^{i n}} \sum_{q \in Q_{r}^{P R C}} \delta_{(r, q, t)} C_{(r, q, t)} \quad \forall t \in T
\end{gathered}
$$

$$
V O C_{t}=C M_{t}+H C_{t}+I C_{t}-T R C_{t}+D C_{t}+N S_{t} \quad \forall t \in T
$$


The variable operating cost is a combination of raw materials costs $\left(\mathrm{CM}_{t}\right)$, cost for the production of useful product state $\left(\mathrm{HC}_{\mathrm{t}}\right)$, inventory cost $\left(\mathrm{IC}_{\mathrm{t}}\right)$, transfer costs between regions $\left(\mathrm{TRC}_{\mathrm{t}}\right)$, penalty for disposal of unwanted state to the environment $\left(\mathrm{DC}_{\mathrm{t}}\right)$, cost for unmet demands $\left(\mathrm{NS}_{\mathrm{t}}\right)$, which are represented by Equations (16-21), respectively.

$$
\begin{gathered}
C M_{t}=\sum_{r \in R^{i n}} \sum_{s \in S_{r}^{F}} \sum_{p \in P_{s}^{F}} \sum_{q \in\left(Q_{r}^{E} \cap Q_{s} \cap Q p\right)} \psi_{(r, s, p, q, t)} M_{(r, r, p, q, t)} \quad \forall t \in T \\
H C_{t}=\sum_{r \in R^{i n}} \sum_{s \in S_{r}} \sum_{p \in P_{s}^{+}} \sum_{q \in\left(Q_{z}^{P R C} \cap Q_{p}\right)} \pi_{(r, s, p, q, t)} M_{\left(r, r^{\prime}, p, q, t\right)} \quad \forall t \in T \\
I C_{t}=\sum_{r \in R^{i n}} \sum_{s \in S^{G}{ }_{r}} \lambda_{(r, s, t)} G_{(r, s, t)} \quad \forall t \in T \\
T R C_{t}=\sum_{r^{\prime} \in R_{r} \in R_{r^{\prime}}^{T R}} \sum_{s \in\left(S r \cap S r^{\prime}\right)} \sum_{p \in P_{s}^{T R}} \sum_{q \in\left(Q_{(r, r)}^{T R} \cap Q p\right)} \vartheta_{\left(r^{\prime}, r, s, p, q, t\right)} M_{\left(r^{\prime}, r, p, q, t\right)} \quad \forall t \in T \\
D C_{t}=\sum_{r \in R^{i n}} \sum_{s \in S_{r}^{D}} \lambda_{(r, s, t)}^{D} D_{(r, s, t)} \quad \forall t \in T \\
N S_{(t)}=\sum_{\sum_{(r, s, t)} N_{(r, s, t)} \lambda^{N}} \forall t \in T
\end{gathered}
$$

\subsection{Description of the case study}

The considered ESC consists of eight states $(s 1-s 8)$, where $(s 1, s 8)$ denote the raw material states, which are coal and biomass (wood chips) in this instance. (s2, s3, s6) represent energy material resources, which are obtained after the combination of $s 1$ and $s 8$ have undergone thermochemical conversion. Moreover, these states are tangible and as such are storable. Wood chips have been selected as a source of biomass as these are frequently considered for co-firing with coal to achieve a reduction in $\mathrm{CO}_{2}$ emissions. Commonly, 1-10\% biomass is co-fired in coal-fired power plants in these circumstances (IEA, 2013). Biu et al. (2018) stated that co-firing biomass led to an increase 
both in quality and quantity of waste heat recovered from exhaust gases, which invariably is one of the avenues for the improvement of energy efficiency in bioenergy with carbon capture and storage (BECCS) system. Furthermore, they stated that there was an appreciable reduction in $\mathrm{SO}_{\mathrm{x}}$ emissions when there was an increment in co-firing ratio of biomass as well as when coal with low sulphur content was used. Additionally, Furubayashi and Nakata (Furubayashi and Nakata, 2018) optimised the renewable material and transportation pathways for biomass using the Geographic Information System in Tohoku region (Japan). They recorded the smallest energy consumption $(3.8 \mathrm{GJ} / \mathrm{t})$, lowest supply cost $(1558 \mathrm{JPY} / \mathrm{GJ})$ and largest $\mathrm{CO}_{2}$ reduction $\left(252 \mathrm{ktCO}_{2} / \mathrm{y}\right)$ in case of woodchips, in comparison to wood pellets and torrefied pellets.

A direct method of co-firing biomass with coal in the combustion chamber of the boiler is assumed in the model. In essence, for a greater level of simplicity and cost effectiveness of the process in a pulverised coal and biomass co-fired CHP plant, biomass and coal could be mixed on the coal conveyor belt and the mixture is subsequently fed into the boiler (Zafar, 2019). Furthermore, ( $s 5$, s7) are the states representing energy form that is either heat, electricity or both and cannot be stored. The unwanted substance state, which can also be seen as a pollutant, is represented by state $(s 4)$.

Additionally, the considered ESC includes seven tasks $(p 1-p 7)$ that are described as exploitation tasks $(p 1, p 7)$, conversion tasks $(p 2, p 4, p 5)$ and transfer tasks $(p 3, p 6)$. Also, the ESC comprises eleven technologies that are associated with each task denoted by $(q 1-q 11)$. Technologies $(q 1, q 10)$ are exploitation technologies, $(q 2, q 5, q 6, q 7, q 8)$ are conversion technologies, (q3, q4, q9) are the transfer technologies and (q11) represents the storage technology. The storage technologies are also associated with the raw materials and energy material resources states given by ( $q$-s01, $q$-s 08 , $\left.q-\mathrm{s} O 2 \_1, q-\mathrm{s} 02 \_2, q-s 03, q-s 06\right)$. 
There are 20 equally distributed yearly time horizons and the tasks take place in three regions, of which two $(r 1, r 2)$ are internal regions, while the third (r3) is an external region. The conversion process $(p 2)$ can be linked to gasification, which is one of the processes for thermochemical conversion of biomass and coal. It involves the conversion of biomass into syngas, which is a primary/intermediate product and a mixture of $\mathrm{H}_{2}$ and $\mathrm{CO}$ which are predominant amongst all other products obtained. Furthermore, the secondary products could be upgraded bio-syngas (with an adjusted $\mathrm{H}_{2} / \mathrm{CO}$ ratio), ethanol with $\mathrm{C}_{3}-\mathrm{C}_{4}$ alcohols, methanol, gasoline, formaldehyde and dimethyl ether (DME). The bio-syngas obtained can then be used in a gas engine for the production of electricity and heat.

Importantly, biogenic carbon (C), which is the emissions related to the natural carbon cycle, as well as those resulting from the combustion, harvesting, digestion and fermentation, decomposition or processing of biologically based materials have not been considered in this case study. Biomass considered in this study (wood chips) is assumed to be sourced locally and sustainably, and as such, its combustion is considered to be carbon neutral. Additionally, Biu et al. (2018) highlighted that if $\mathrm{CO}_{2}$ from biomass combustion is captured and permanently stored, considering that biomass is sustainably sourced, the considered BECCS systems can become carbon negative. 


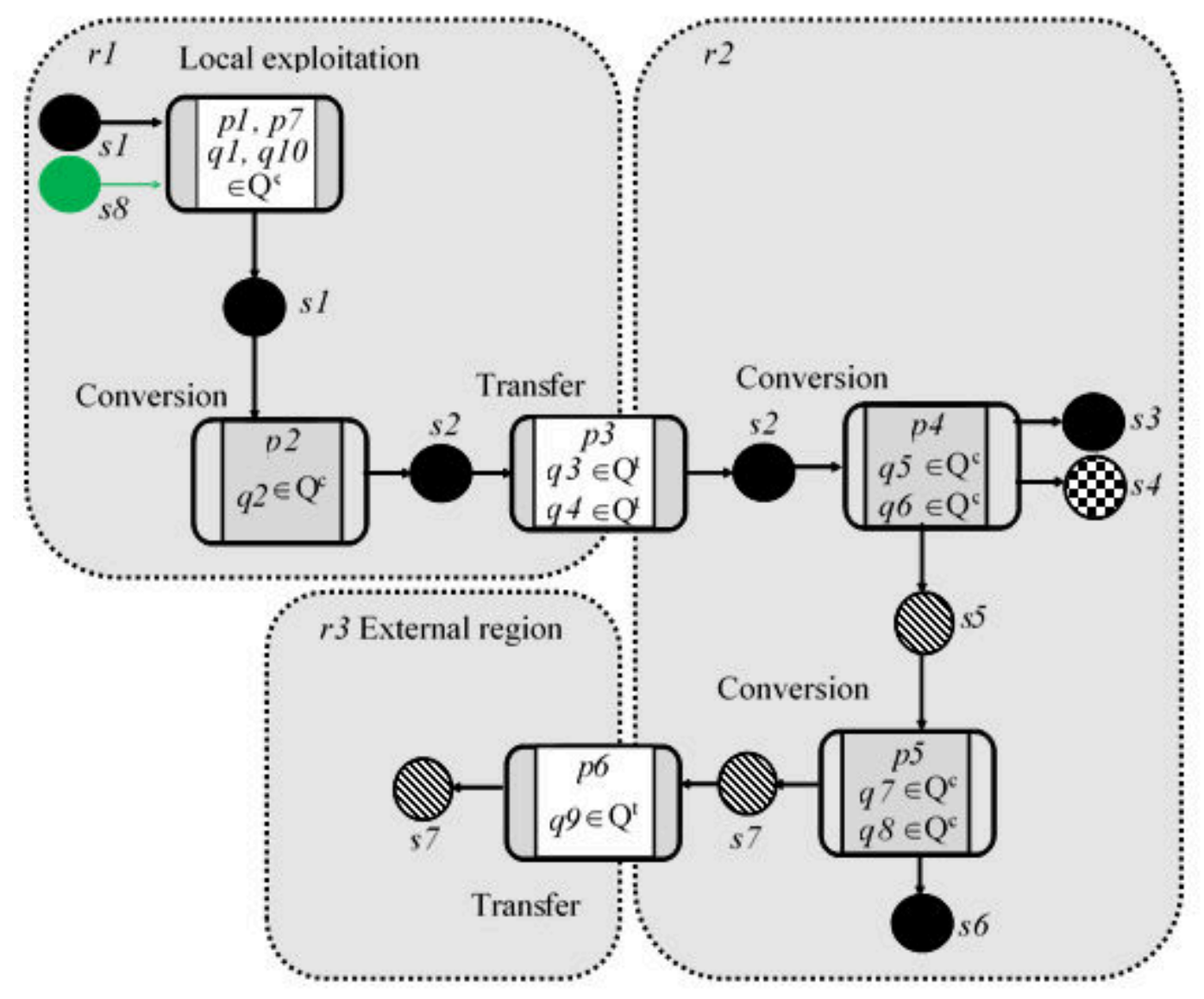

Figure 3: Illustrative energy state-task network for energy supply chain network

The raw material states, $s 1$ and $s 8$ as well as the energy material resources states, $(s 2, s 3, s 6)$ can be stored in storage tanks, while the energy form states, ( $s 5$ and $s 7$ ) cannot be stored. Importantly, the undesired substance $(s 4)$ would not be stored. This is indicated in Table 1. 
Table 1: Storage technologies available per state and region

\begin{tabular}{lcc}
\hline States that are storable $(\boldsymbol{s})$ & Internal region $(\boldsymbol{r} 1)$ & Internal region $(\boldsymbol{r} 2)$ \\
\hline$s 1$ & $q s 1$ & - \\
$s 2$ & $q s 2$ & $q s 2$ \\
$s 3$ & - & $q s 3$ \\
$s 6$ & - & $q s 6$ \\
$s 8$ & $q s 8$ & - \\
\hline
\end{tabular}

Table 2: Minimum and maximum capacity expansion level of associated technology, investment cost for technology establishment, cost for technology increment and fixed operating cost for total installed technology (Zulkafli and Kopanos, 2018)

\begin{tabular}{|c|c|c|c|c|c|c|}
\hline Technology & $\gamma^{\min }$ & $\gamma^{\max }$ & $\begin{array}{c}\mathcal{\varepsilon}_{(\mathbf{r}, \mathbf{q}, \mathbf{t})} \\
\text { (m.u./unit) }\end{array}$ & $\begin{array}{c}\mathcal{E}_{(\mathbf{r}, \mathbf{q}, \mathbf{t})} \\
\text { (m.u./unit) }\end{array}$ & $\begin{array}{c}\boldsymbol{\delta}_{(\mathbf{r}, \mathbf{q}, \mathbf{t})} \\
\text { (m.u./unit) }\end{array}$ & $\begin{array}{c}\pi_{(\mathbf{r}, \mathbf{s}, \mathbf{p}, \mathbf{q}, \mathbf{t})} \\
\text { (m.u./unit) }\end{array}$ \\
\hline$q 1$ & 5 & 50 & $(1,326-1,820)$ & $(1,122-1,540)$ & - & - \\
\hline$q 2$ & 5 & 50 & 20,000 & $(1,800-2,000)$ & 15 & 12 \\
\hline$q 3$ & 0 & 30 & 1,000 & $(580-650)$ & 0 & 0 \\
\hline$q 4$ & 0 & 30 & 1,000 & $(550-650)$ & 0 & 0 \\
\hline$q 5$ & 10 & 40 & 28,000 & $(3,950-4,139)$ & 20 & 20 \\
\hline$q 6$ & 10 & 40 & 25,000 & 3,500 & 40 & 25 \\
\hline$q 7$ & 5 & 30 & 20,000 & 3,000 & 30 & 30 \\
\hline$q 8$ & 5 & 30 & 26,000 & 2,600 & 25 & 40 \\
\hline$q 9$ & 0 & 50 & 8,000 & 800 & 0 & 0 \\
\hline$q 10$ & 5 & 50 & $(1,458.6-2,002)$ & $(1,122-1,540)$ & - & - \\
\hline
\end{tabular}

From Table 2, all parameters and values stated, which include the bounds on the capacity expansions levels (in relative units) for local exploitation ( $q 1, q 10)$, conversion $(q 2, q 5, q 6, q 7, q 8)$, transfer technologies $(q 3, q 4, q 9)$, denoted by $\gamma^{\min }$ and $\gamma^{\max }$, fixed operating cost for the total installed capacity of technology $\mathrm{q}(\delta)$ and those associated to states production through conversion technologies $(\pi)$, were obtained from Zulkafli \& Kopanos (2018), while the values of investment cost for technology establishment $\left(\varepsilon^{0}\right)$ and that required to increase the capacity of a technology $(\varepsilon)$, were obtained as solution from the model formulation after incorporating the earlier stated values from (Zulkafli and Kopanos, 2018). 


\section{Results and discussion}

The normalised demand profile graph (Figure 4) was plotted by using the maximum demand for useful/final products over the entire planning horizon of each state $(s)$ and region $(r)$ as a baseline for total demands made in each time period. From the energy resource produced in the internal region $(r 2 . s 3)$ there was no demand in the first time period $(t 1)$ because, the syngas produced was an intermediate product. However, this product, which is a mixture of $\mathrm{CO}$ and $\mathrm{H}_{2}$, had to undergo further treatment to convert it into biogas, in order to obtain a secondary product with an adjusted $\mathrm{CO} / \mathrm{H}_{2}$ ratio for direct use in boilers and gas turbines. Additionally, it could act as a precursor for the synthesis of a large range of other chemicals (Zafar, 2018). This is also applicable to energy resource $(s \sigma)$ which is also upgraded biogas for which there was no demand in the first time period $(t 1)$. However, the maximum demand for $s 6$ was recorded at the time period $t 13$, with a value of 106 relative units (ru) that is equivalent to $1 \mathrm{ru}$ in the normalised demand profile graph. Furthermore, the results presented in Figure 4 show that energy form state $s 7$ in region $r 2(r 2 . s 7)$, which represents electricity, had the highest demand in time period $t 14$ with a value of $106 \mathrm{ru}$. From the trend shown in Figure 4, higher demands for products occurred at later time periods, between $t 13$ and $t 20$, and could be attributed to the production of useful products states at those times. However, energy resource state $s 7$ in region $r 3$ (r3.s7) recorded its highest demand at the last time period $(t 20)$. This occurred as a result of transfer of energy form state $s 7$ from an internal region $r 2$ to an external region $r 3$. Finally, the scenario recorded at this state and region confirmed the non-availability of associated inventory. 


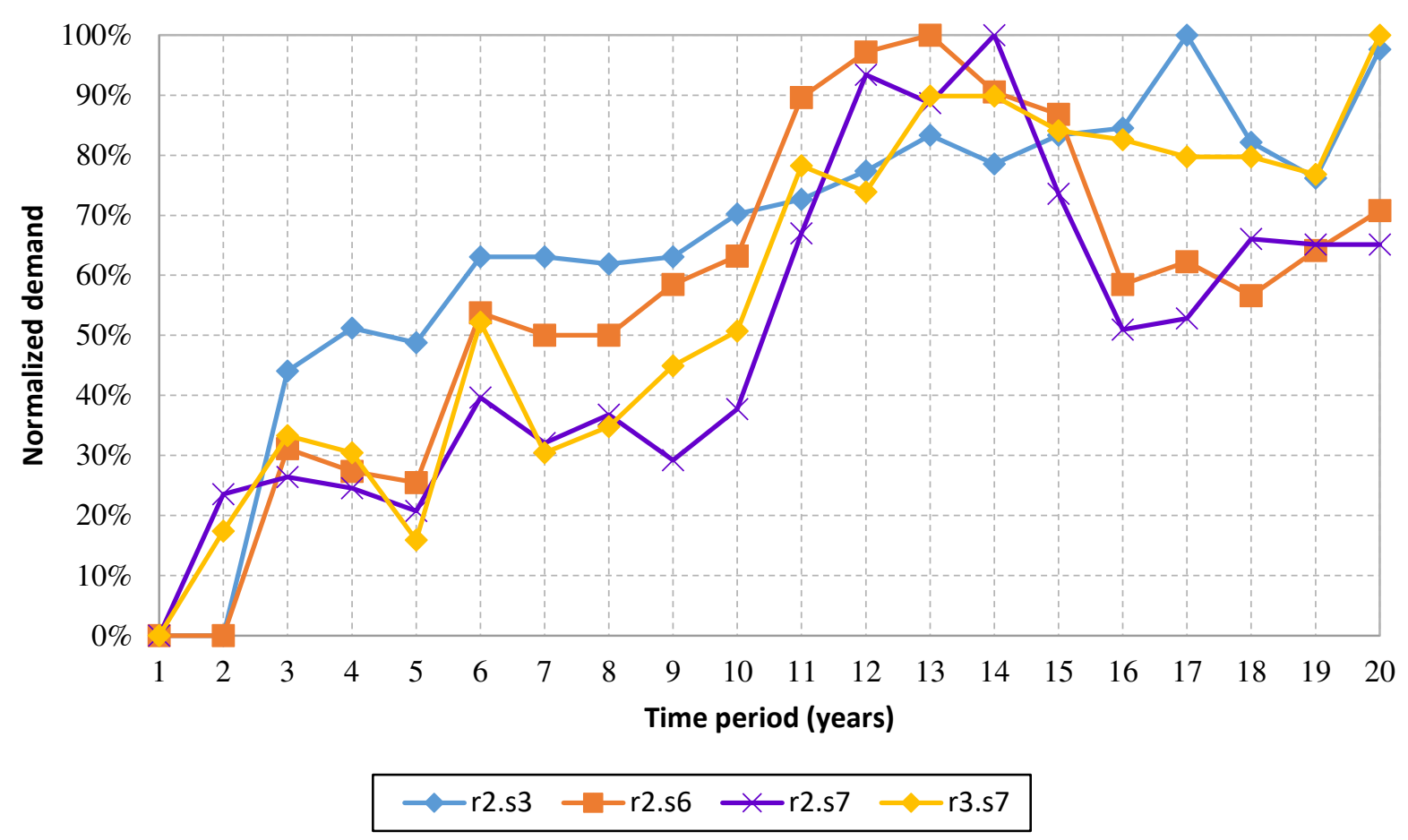

Figure 4: Normalized demand profile graph for energy resource produced in both internal regions $(r 2 . s 3, r 2 . s 6, r 2 . s 7)$ and external region $(r 3 . s 7)$

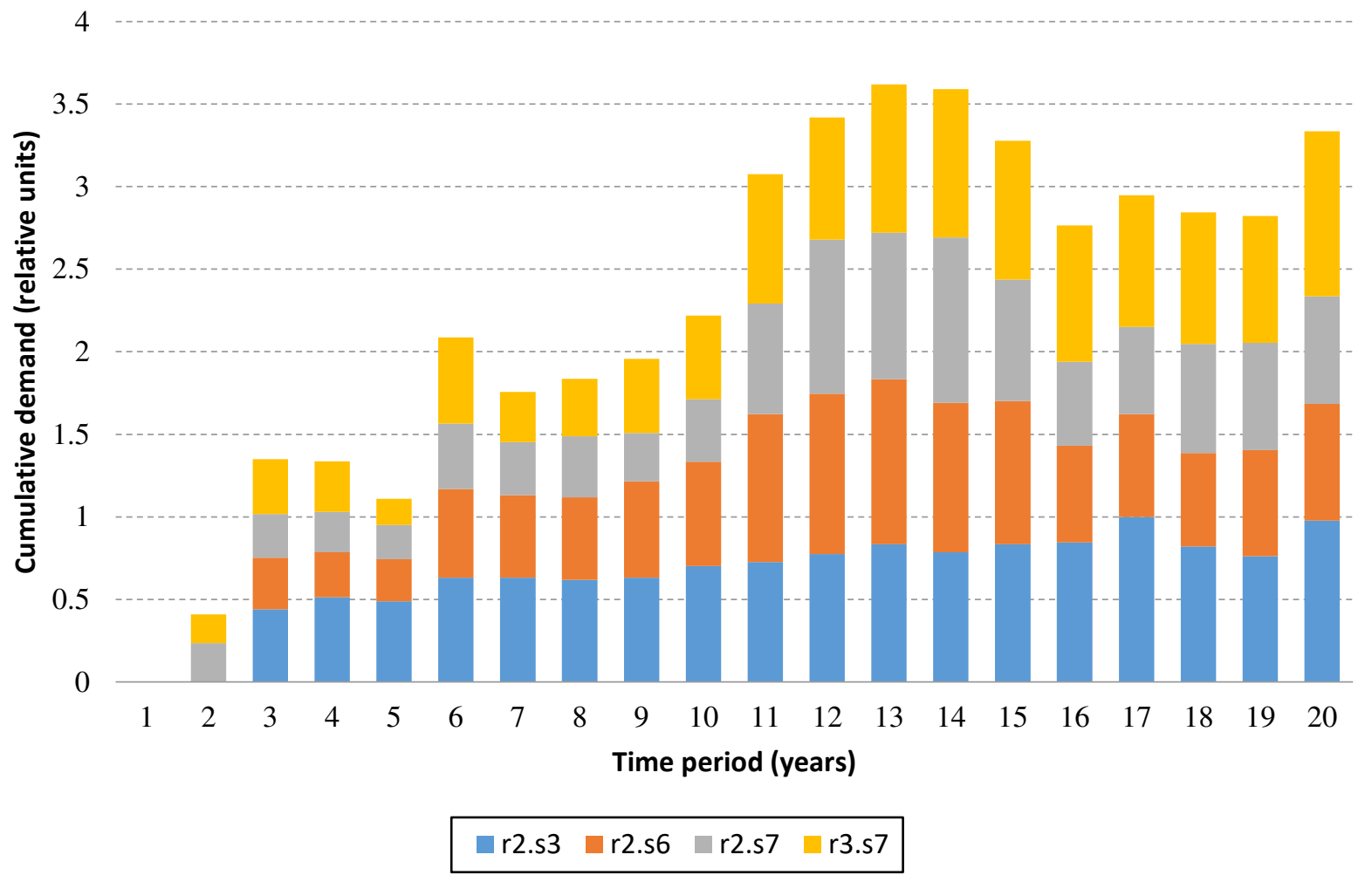

Figure 5: Cumulative demand graph for states $(s)$ in regions $(r)$ obtained by dividing the individual demand at every time period by the maximum value at each state and region. 


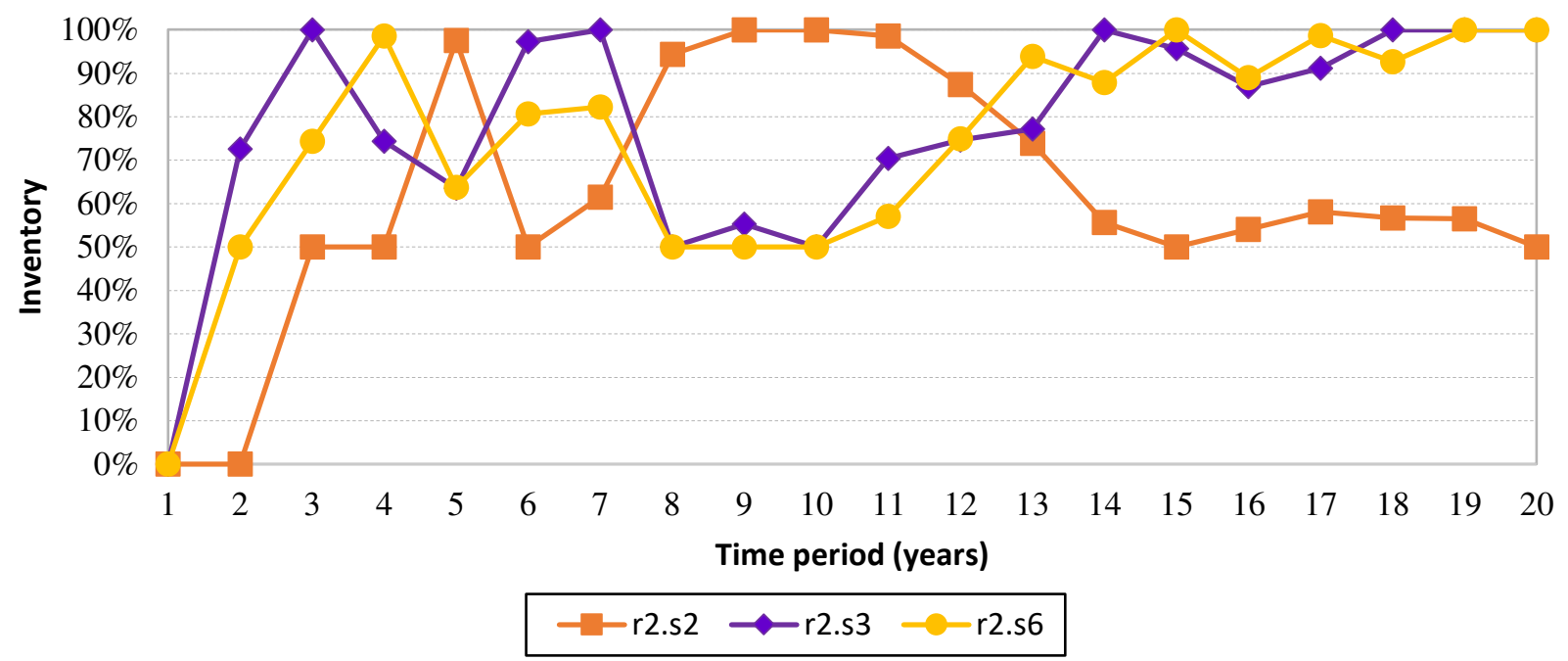

Figure 6: Inventory profile graph for energy material resource states $(s)$ that can be stored in regions $(r)$ where applicable.

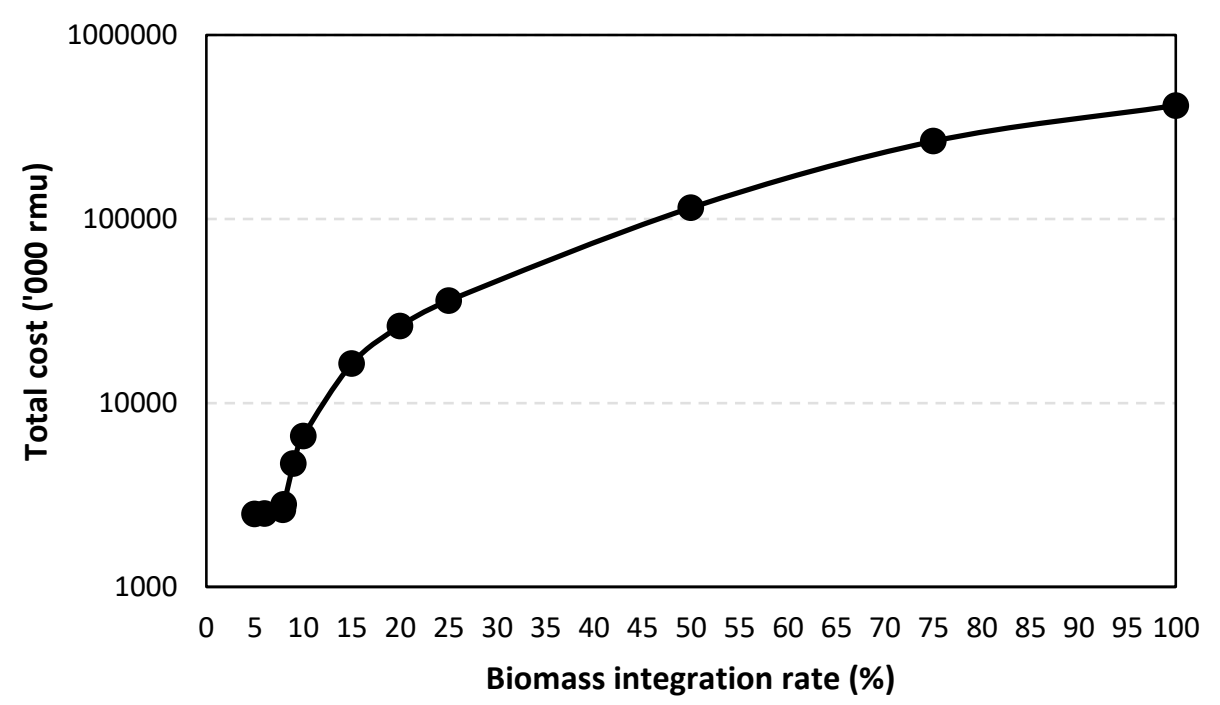

Figure 7: Effect of biomass fraction in the mixed solid fuel on the total cost of energy supply chain network

The optimal solution of 2,515,206 relative money units ( $\mathrm{rmu}$ ), representing the overall cost of the ESC was obtained by solving the MILP model for only coal-fired power plant. This was obtained using the CPLEX 12 optimisation solver of the GAMS, on an Intel (R) core ${ }^{\text {TM }}$ i5-6200U CPU @ 2.40GHz system with a zero optimality gap and under a negligible computational time. However, 
under same modelling but with slightly modified optimisation conditions, the co-fired CHP plant utilizing biomass and coal as energy material resources returned a value of 2,630,260 rmu.

Integration of $7.9 \%$ of biomass material resource shows a decrease of $4.32 \%$ in the emissions costs of the considered ESC network. As indicated in Figure 7, even though increased biomass fraction in the mixed solid fuel in the ESC resulted in a substantial reduction in emissions cost, at above $9 \%$ of biomass in the ESC, a sharp increase in the overall cost of the ESC network was observed. Therefore, biomass co-firing with coal was not economically justifiable at that point. Importantly, at the biomass fractions in the mixed solid fuel of $5-6 \%(2,495,058-2,503,809 \mathrm{rmu})$, the total cost of the ESC network was marginally lower than that of the ESC network without biomass integration $(2,515,206 \mathrm{rmu})$. The total cost of ESC network at the biomass fractions of $8 \%$ was shown to increase to 2,811,267 rmu, a substantial increase from 2,630,260 rmu at $7.9 \%$. Importantly, this is in line with the maximum biomass fraction of $10 \%$ reported by (Knapp et al., 2019). Therefore, the latter has been used in further analysis. Overall, such variation in the total cost of the ESC network with biomass fraction can be associated to subsequent reduction of the cost associated with emissions in the ESC network, as biomass, which is considered as a carbon neutral energy material resource, is assumed to have been sourced locally. As a result, its conversion process is associated with less $\mathrm{CO}_{2}$ emissions compared to that of coal. Moreover, biomass co-firing is capable of reducing the nitrogen oxides $\left(\mathrm{NO}_{\mathrm{x}}\right)$ as well as sulphur oxides $\left(\mathrm{SO}_{\mathrm{x}}\right)$ that are released during thermochemical conversion of coal. Yet, at higher biomass fractions, the cost associated with its transportation and losses during transportation resulted in increased total cost of the ESC network.

Figure 5 shows the total demand for states (s) in regions (r) that apply to them. $s 3$ and $s 6$ are storable energy material resources obtainable in region $r 2$, while $s 7$ represents an energy form 
state, which is in demand and cannot be stored, and thereby necessitating its transfer from internal region $r 2$ to external region $r 3$. Figure 5 reveals that the highest cumulative demand for useful products states was obtained in time period $t 13$ with a value of 3.62 relative units. For storable energy materials with high demands, storage level for storable products will be low and vice-versa as shown in the inventory profile graph (Figure 6).

The Gantt chart shown in Figure 8 depicts the ideal planning for capacity expansion in the considered planning horizon (binary variables, $Z, Z^{T R}, Z^{G}$ ). In the planning, local exploitation ( $q 1$, $q 10)$, conversion $(q 2, q 5, q 6, q 7, q 8)$, transfer $(q 3, q 4, q 9)$ and storage technologies $(q s 2, q s 3, q s 6)$ are all considered. Furthermore, in Figure 8, all local exploitation, conversion and transfer technologies were established in the first time period as there was no consideration for their initial installation, the only exception to this is storage technology which is not established until there has been production of storable states. There was no storage in region $r 1$, but exploitation, conversion and transfer technologies were evident as demand for these states occurred from the second time period onwards. Additionally, the results revealed that the cost of establishing these technologies was lower in the first time period, compared to subsequent time periods. This, however, can be attributed to the amount of states produced in the considered time periods. It is important to highlight that the storage technologies were established in region $r 2$, following the production of storable states. Capacity expansions occurred in the early time periods, for example, conversion capacity expansions occurred from time period 1 to time period 13 . This can be attributed to the fact that the cost of increasing the capacities of available technology was lower in the earlier time periods than in the later time periods, which may have arisen from the need for the increased size of technology to meet the increase in demand. Importantly, the results show that the latest time period for the establishment of the transfer technology $q 9$ was at time period 12, as the investment 
cost for the increment of transfer technology $\left(\varepsilon_{(r, q, t)}\right)$ started to increase from time period 14. Also, there was no establishment of storage technologies in region 1, as shown in the Gantt chart. With the establishment of technologies in time period 1, the storage technology, qs 2 , which occurred in region 2, was first established in the time period 3 after there has been production of storable states, while storage technologies, $q s 3$ and $q s 6$ were first established in the time period 2. Additionally, there were capacity expansions for storage technologies $q s 3$ and $q s 6$ in latter time periods ( $t 19$ and t20) which was due to increased production of storable states.

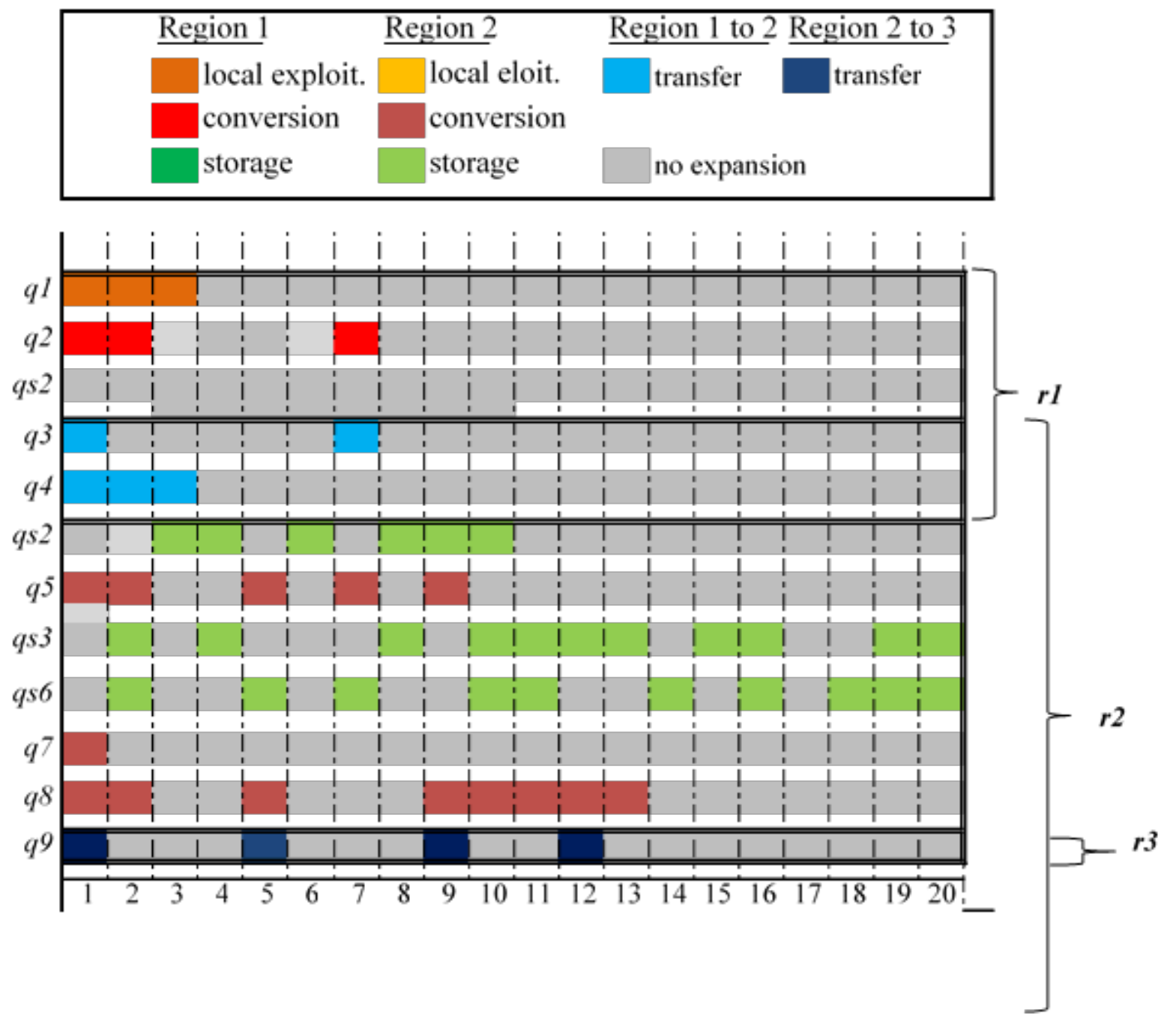

Time periods (years)

Figure 8: Overall capacity expansion planning per associated technologies $(q)$ in regions $(r)$ and at time periods $(t)$ 
The representation of the costs components of the considered ESC network (Figures 9a and 9b) revealed the fixed assets cost had the most significant contribution to the total ESC network cost, with a value of $1,575,429 \mathrm{rmu}$, which is equivalent to about $60 \%$ of the overall cost of the ESC networks with biomass integration. This is only $0.35 \%$ higher compared to the fixed asset cost of the ESC network based on coal $(1,569,934 \mathrm{rmu})$. Such a small increase in the fixed asset cost was obtained due to the assumption that biomass (wood chips) was co-fired directly in the existing coal-fired CHP plant using the same combustion chamber. It is worth noting that the fixed asset cost of the co-fired CHP plant comprises of the cost of land, equipment (combustion chamber, steam cycle), power house building, testing and commissioning. The variable costs for the ESC network with biomass was 455,964 rmu (17\%), 25\% higher compared to that of the ESC network based only on coal $(364,576 \mathrm{rmu}, 14 \%)$. This could be associated to a higher price and volume of biomass required to achieve the same energy output as the variable cost is a combination of raw materials, production, inventory, transfer and costs associated with disposal of states in the network. Furthermore, the costs of emissions and fixed transfer in the ESC network with biomass integration were estimated to be $291,727.7 \mathrm{rmu}(11 \%)$ and $165,839.5 \mathrm{rmu}(6 \%)$ respectively. The corresponding figures for the ESC network based only on coal were 304,895 rmu (12\%) and $140,874 \mathrm{rmu}(6 \%)$, respectively. This indicates that biomass integration into the ESC network can reduce the cost of emissions by $4.3 \%$. Finally, the fixed operating cost was estimated to be 141,300 rmu (6\%) and 134,928 rmu (5\%) in the ESC with and without biomass integration, respectively. These results have revealed that technology establishment which falls under the fixed asset cost, amongst other criteria, demands proper optimisation as one of the means of further achieving a reduction in the overall cost of ESC networks. 


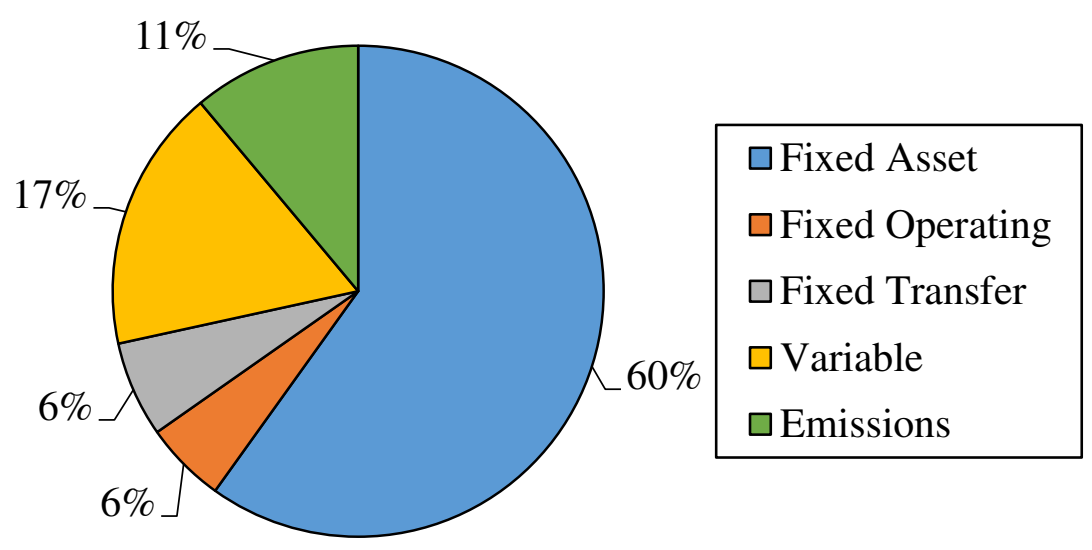

Figure 9a: Total cost breakdown for ESC network with biomass integration

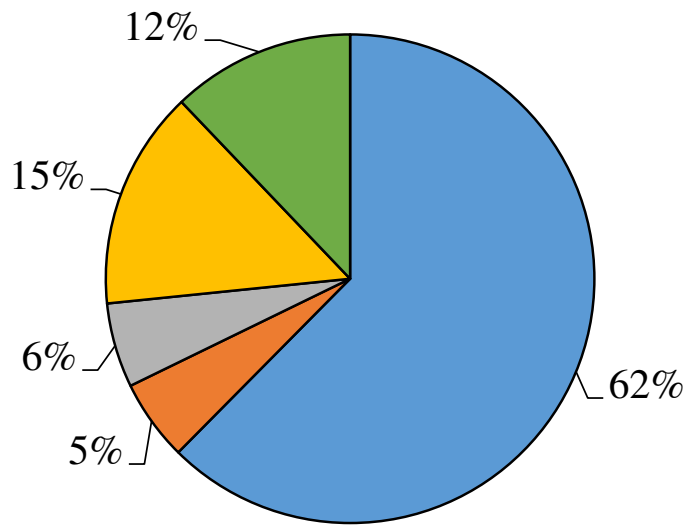

$\square$ Fixed Asset

$\square$ Fixed Operating

$\square$ Fixed Transfer

$\square$ Variable

$\square$ Emissions

Figure 9b: Total cost breakdown for ESC network without biomass integration (coal only)

\section{Conclusions}

The integration of biomass and its co-firing in a CHP plant is one of the most cost-effective method of generating electricity from biomass, achieving significant reductions in emissions. Invariably, this translates to an increased level of energy security, thereby guaranteeing a reduction on the dependence on imported fuel, leading to economic development. This work has focused on minimising the total cost of the ESC network with biomass integration. The results of the optimisation have revealed that at biomass fraction in the mixed solid fuel of $7.9 \%$, the emission 
cost and the total cost of the ESC network will be reduced by $4.32 \%$ and increased by $4.57 \%$ respectively. Although biomass (wood chips) fractions in the mixed solid fuel ranging between $5 \%$ and $8 \%$ could be co-fired with coal to achieve an appreciable level of emission reduction at affordable cost, the biomass value of $7.9 \%$ resulted in more balanced values on the other cost components of the considered ESC network. This was because the cost increment in the assets and operational costs of biomass and coal co-fired CHP plant can be offset by the cost reductions obtained from reduced $\mathrm{CO}_{2}$ emissions. Furthermore, the cost considered in the ESC networks is the overall cost of the supply chain; however, in this particular case study, monetary values were not discounted due to interest rate.

This study showed that, in addition to the environmental benefits realised from biomass integration into the existing ESC network aimed at mitigating climate change due to emissions from thermochemical conversion of fossil fuels, economic benefits are achievable if relevant emissions/carbon trading scheme or carbon tax are implemented. As such, decision makers in the power industry can justify their reasons for co-firing biomass with coal.

Future works could develop this research by:

- considering alternative biomass types;

- considering other base fuels alternative to coal, such as oil or gas;

- incorporating a stochastic approach to quantify effect of uncertainty; and

- accounting for the biogenic emissions.

In addition, with different types of biomass having significantly different physical and chemical compositions that may have a substantial effect on the outcome of processes performed on their ESC networks, it is recommended that further analysis be performed to determine the validity of the current prediction if other types of biomass is used. Finally, further studies should focus on the 
determination of the values of each technology in the network and generation expansion planning with carbon capture and storage technologies.

\section{Nomenclature}

\section{Indices/sets}

$p \in P \quad$ tasks (biomass/coal exploitation, pre-processing, conversion, transfer)

$q \in Q \quad$ Technologies (biomass exploitation, conversion, transfer, storage: intermediate site, infield, storage at the power station

$s \in S \quad$ States (raw materials/biomass, energy material resources, energy forms,)

$t \in T \quad$ Time periods

$r \in R \quad$ Regions (internal and external)

Subsets

\begin{tabular}{|c|c|}
\hline$Q^{\mathrm{E}}$ & Raw materials/biomass exploitation technology \\
\hline $\mathrm{Q}^{\mathrm{C}}$ & Conversion technologies \\
\hline $\mathrm{Q}^{\mathrm{TR}}$ & Transfer technologies \\
\hline $\mathrm{Q}^{\mathrm{G}}$ & Storage technologies (inclusive of intermediate site, infield, storage at power \\
\hline \multicolumn{2}{|r|}{ 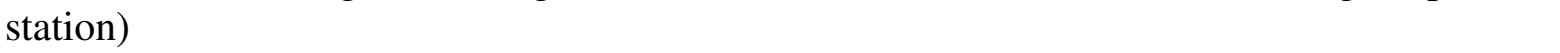 } \\
\hline $\mathrm{Q}_{\mathrm{p}}$ & Technologies that could perform tasks $p$ \\
\hline $\mathrm{Q}_{\mathrm{s}}$ & Technologies that involve states $s$ \\
\hline $\mathrm{Qr}_{\mathrm{r}}$ & Technologies that could be installed in regions $r$ \\
\hline $\mathrm{Q}_{\mathrm{r}}^{\mathrm{E}}$ & Raw materials/biomass exploitation technologies in region $r$ \\
\hline$Q^{P R C}$ & $\begin{array}{l}\text { Pre-processing and conversion technologies, and biomass/local exploitation } \\
\text { technologies in region } r\end{array}$ \\
\hline $\mathrm{Q}^{\mathrm{TR}}\left(\mathrm{r}, \mathrm{r}^{\prime}\right)$ & Transfer technologies that can transfer states from region $r$ to $r$ \\
\hline $\mathrm{Q}_{(\mathrm{s}, \mathrm{r})}^{\mathrm{G}}$ & Storage technologies for states in region $r$ \\
\hline $\mathrm{P}_{\mathrm{S}}^{-}$ & Tasks that consume states (input state) \\
\hline $\mathrm{P}_{\mathrm{s}}^{+}$ & Tasks that produce states (output state) \\
\hline $\mathrm{P}_{\mathrm{s}}^{\mathrm{T}}$ & Tasks that could transfer state $s$ \\
\hline$P_{s}^{F}$ & Tasks involving raw material state \\
\hline $\mathrm{S}_{\mathrm{r}}$ & States that are present in region $r$ \\
\hline$S^{F}$ & Fossil fuel raw material state \\
\hline $\mathrm{S}_{\mathrm{r}}^{\mathrm{U}}$ State & $s$ that have demand in region $r$ (represented as demand or useful product states) \\
\hline $\mathrm{S}_{\mathrm{r}}^{\mathrm{G}}$ & States $\mathrm{s}$ that can be stored in region $r$ \\
\hline $\mathrm{S}^{\mathrm{rm}}$ & States that are considered as raw materials \\
\hline $\mathrm{S}^{\mathrm{rm}}$ renew & Renewable material state \\
\hline$\overline{\mathrm{S}_{\mathrm{r}}} \mathrm{D}$ & States s that can be disposed in region $r$ \\
\hline $\mathrm{R}^{\text {in }}$ & Internal regions of the energy supply chain networks \\
\hline $\mathrm{R}^{\mathrm{ex}}$ & External regions of the energy supply chain networks \\
\hline $\mathrm{R}_{\mathrm{r}}^{\mathrm{TR}}$ & Regions that can transfer states between each other \\
\hline
\end{tabular}




\section{Parameters}

$\alpha_{(r, r, p, q, t)}$ Bounds on the available capacities for both conversion and transfer tasks

$\beta_{(r, s, t)} \quad$ Bounds on inventory levels on states that can be stored $s \in S^{G}$

$\beta^{0}{ }_{(r, s)} \quad$ Initial level of inventory for all states in all regions

$\delta_{(r, q, t)} \quad$ Fixed operating cost for the total installed capacities of technology $q$

$\gamma_{(r, q, t)} \quad$ Bounds on allowable expansion levels for pre-processing, conversion and storage technologies

$\gamma_{\left(r, r^{\prime}, t\right)}^{T R} \quad$ Bounds on allowable expansion levels for transfer technologies $q \in Q^{T R}$

$\varepsilon_{(r, q, t)}^{0} \quad$ Initial investment cost required to establish a technology

$\varepsilon_{(r, q, t)} \quad$ Investment cost needed to expand the capacity of an already established technology

$\zeta_{(r, s, t)}$

Demand for useful products states $s \in S^{u}$ in region $\mathrm{r}$ in time period $t$

$\eta_{(r, s, t)} \quad$ Co-efficient of deterioration for states that can be stored $s \in S^{G}$

$\vartheta_{\left(r^{\prime}, r, s, p, q, t\right)}$ Transfer cost for states considered as useful products $s \in S^{u}$ to points of demand

$\kappa_{(s, p, q)} \quad$ Coefficient for input/output states for tasks that could be performed by technology

$\mathrm{q}$

$\lambda_{(r, s, t)} \quad$ coefficient of holding cost for storable states

$\lambda_{(r, s, t)}^{D} \quad$ coefficient of penalty for causing pollution through the disposal of unwanted substances into the environment.

$\lambda^{N} \quad$ coefficient of penalty cost for unmet demand.

$\mu_{(r, q, t)} \quad$ Time of installation for technology $q$ in region $r$ or the duration of constructing an additional facility, for an implementation start in period $t$

$\mu_{\left(r, r^{\prime}, q, t\right)}^{T R}$ Time for installation for a transfer technology that connects region $r$ and $r$ ' for an implementation start in period $t$

$\pi_{(r, s, p, q, t)} \quad$ cost of states production through conversion technology

$\psi_{(r, s, p, q, t)} \quad$ Raw material cost

$\omega_{(r, s, t)} \quad$ Maximum available amount of raw material

$\varphi_{(r, q)} \quad$ Initial installed capacity for biomass exploitation, $q \in Q^{E}$, pre-processing and conversion technologies, $q \in Q^{P R C}$ in region $r$

$\varphi_{(r, s, q)}^{G} \quad$ Initial installed capacity for storage technology $q \in Q^{B}$ in region $r$

$\varphi_{\left(r, r^{\prime}, q\right)}^{T R} \quad$ Initial installed capacity for transfer technology $q \in Q^{T R}$ that connects two regions 


\section{Continuous variables}

$C_{(r, q, t)} \quad$ Overall capacity of conversion or local/biomass exploitation technology $q$ in region $r$, at time period $t$

$D_{(r, s, t)} \quad$ Quantity of disposable states

$E_{(r, q, t)} \quad$ Capacity increase of conversion technology $q$ in region $\mathrm{r}$, at time interval $t$

$C_{(r, s, q, t)}^{G}$ Overall capacity of storage technology $q$ that can store states in region $r$, at time interval $\mathrm{t}$

$E_{(r, s, q, t)}^{G}$ Capacity increase of storage technology that can store states in region $r$, at time interval $\mathrm{t}$

$C_{\left(r, r^{\prime}, q, t\right)}^{T R}$ Overall capacity of transfer technology q that can that can transfer states from region $r$ to region $r$ ' in time period $t$

$E_{\left(r, r^{\prime}, q, t\right)}^{T R}$ Capacity increase of transfer technology $q$ that can that can transfer states from region $r$ to region $r$ ' in time period $t$.

$M_{\left(r, r^{\prime}, q, t\right)} \quad$ Amount/Quantity of states pre-processed, converted or transferred by task $p$, with the use of technology $q$ from region $r$ to $r$ ' in period $t$

$G_{(r, s, t)} \quad$ stock of states that remain in region $\mathrm{r}$ at the end of time period $t$

$F A C_{t} \quad$ Fixed asset cost in time period $t$

$F A C_{t}^{T R} \quad$ Transfer network cost in time period $t$

$F_{t} \quad$ Fixed operating cost in time period $t$

$V O C_{t} \quad$ Variable operating cost in time period $t$

$C M_{t} \quad$ Cost of raw materials at every time period $t$

$H C_{t} \quad$ Cost of producing useful product states' at time period $t$

$I C_{t} \quad$ Cost of inventory for states in time period $t$

$T R C_{t} \quad$ Transfer cost for useful product states within internal regions and that of sales to external regions

$D C_{t} \quad$ Cost of disposing unwanted states to the environment (penalty)

$N_{(r, s, t)} \quad$ Quantity of states with unmet demands

$N S_{t} \quad$ Penalty (cost) for no-sales, i.e unmet demands

\section{Binary variables}

$V_{(r, q, t)}=1$, if biomass exploitation, pre-processing and conversion technologies are established for the first time in region $r$ at time period $t$, zero if otherwise.

$V_{(r, s, q, t)}^{G} \quad=1$, if storage technology $q$ for state $s$ is established for the first time in region $r$ at time period $t$, zero if otherwise. 
$Z_{(r, q, t)} \quad=1$, if capacity of biomass exploitation, pre-processing and conversion technology $\mathrm{q}$ begins installing in region $r$ at time period $t$, zero if otherwise.

$Z_{(r, s, q, t)}^{G}=1$, if capacity of storage technology q for state $s$ begins installing in region $r$ in time period $t$, zero if otherwise.

$Z_{\left(r, r^{\prime}, q, t\right)}^{T R}=1$, if capacity of transfer technology $q$ starts installing in region $r$ in time period $t$, zero if otherwise.

$\begin{array}{ll}\text { Abbreviations } & \\ \text { BECCS } & \text { Bioenergy with carbon capture and storage } \\ \text { BSC } & \text { Biomass supply chain } \\ \text { CHP } & \text { Combined heat and power plant } \\ \text { DME } & \text { Di-methyl ether } \\ \text { ESC } & \text { Energy supply chain } \\ \text { GAMS } & \text { General algebraic modelling system } \\ \text { MILP } & \text { Mixed-integer linear programming } \\ \text { NMIP } & \text { Nonlinear mixed-integer programming } \\ \text { STN } & \text { State-task network }\end{array}$

\section{Acknowledgement}

O.C. Murele would like to express her appreciation to Petroleum Technology Development Fund, Nigeria (PTDF/ED/PHD/MOC/876/16) for providing sponsorship for the realization of this work. 


\section{References}

Awudu, I., Zhang, J., 2012. Uncertainties and sustainability concepts in biofuel supply chain management: A review. Renew. Sustain. Energy Rev. 16(2), 1359-1368.

Babazadeh, R., 2016. Optimal design and planning of biodiesel supply chain considering nonedible feedstock. Renew. Sustain. Energy Rev. 75, 1089-1100.

Banasik, A., Bloemhof-Ruwaard, J.M., Kanellopoulos, A., Claassen, G.D.H., van der Vorst, J.G.A.J., 2018. Multi-criteria decision making approaches for green supply chains: a review. Flex. Serv. Manuf. J. 30(3), 366-396.

Bui, M., Fajardy, M., Mac Dowell, N., 2018. Bio-energy with carbon capture and storage (BECCS): Opportunities for performance improvement. Fuel 213, 164-175.

Duarte, A.E., Sarache, W.A., Costa, Y.J., 2014. A facility-location model for biofuel plants: Applications in the Colombian context. Energy 72, 476-483.

Eksioglu, S.D., Karimi, H., 2015. Biofuels \& Bioenergy. J. Fundam. Renew. Energy Appl. 5, 4541.

Ekşioğlu, S.D., Karimi, H., Ekşioğlu, B., 2016. Optimization models to integrate production and transportation planning for biomass co-firing in coal-fired power plants. IIE Trans. 48(10), 901-920.

Energy Exchange, 2018. The energy supply chain. Available at: https:/www.eex.gov.au/largeenergy-users/energy-management/energy-procurement/energy-pricing/the-energy-supplychain (accessed 27/02/2019).

EC (2015). Paris Agreement. European Commission, Brussles, Belgium.

Furubayashi, T., Nakata, T., 2018. Cost and $\mathrm{CO}_{2}$ reduction of biomass co-firing using waste wood biomass in Tohoku region, Japan. J. Clean. Prod. 174, 1044-1053.

Han, S.K., Murphy, G.E., 2012. Solving a woody biomass truck scheduling problem for a transport company in Western Oregon, USA. Biomass Bioenergy 44, 47-55.

IEA (2018). Global energy and $\mathrm{CO}_{2}$ status report. IEA Publishing, Paris, France.

IEA, 2013. Biomass Co-firing: Technology brief. IEA, Paris.

Knapp, S., Güldemund, A., Weyand, S., Schebek, L., 2019. Evaluation of co-firing as a costeffective short-term sustainable $\mathrm{CO}_{2}$ mitigation strategy in Germany. Energy. Sustain. Soc. $9,32$.

Kondili, E., Pantelides, C.C., Sargent, R.W.H., 1993. A general algorithm for short-term scheduling of batch operations-I. MILP formulation. Comput. Chem. Eng. 17(2), 211-227.

Miret, C., Chazara, P., Montastruc, L., Negny, S., Domenech, S., 2016. Design of bioethanol green supply chain: Comparison between first and second generation biomass concerning economic, environmental and social criteria. Comput. Chem. Eng. 85, 16-35.

Pérez-Fortes, M., Laínez-Aguirre, J.M., Bojarski, A.D., Puigjaner, L., 2014. Optimization of pretreatment selection for the use of woody waste in co-combustion plants. Chem. Eng. Res. Des. 92(8), 1539-1562.

REN21, 2018. Renewables 2018 global status report. Renewable Energy Policy Network for the 
$21^{\text {st }}$ Century, Paris, France

Rentizelas, A.A., Tolis, A.J., Tatsiopoulos, I.P., 2009. Logistics issues of biomass: The storage problem and the multi-biomass supply chain. Renew. Sustain. Energy Rev. 13(4), 887-894.

Ritchie, H. and Roser, M. (2018). Fossil Fuels. Available at: https://ourworldindata.org/fossilfuels (accessed 27/02/2019),

Roni, M.S., Eksioglu, S.D., Searcy, E., Jha, K., 2014. A supply chain network design model for biomass co-firing in coal-fired power plants. Transp. Res. Part E Logist. Transp. Rev. 61, $115-134$.

Sharma, B., Ingalls, R.G., Jones, C.L., Khanchi, A., 2013. Biomass supply chain design and analysis: Basis, overview, modeling, challenges, and future. Renew. Sustain. Energy Rev. $24,608-627$.

Warren, T.J.B., Poulter, R., Parfitt, R.I., 1995. Converting biomass to electricity on a farm-sized scale using downdraft gasification and a spark-ignition engine. Bioresour. Technol. 52(1), 95-98.

Yue, D., Pandya, S., You, F., 2016. Integrating hybrid life cycle assessment with multiobjective optimization: a modeling framework. Environ. Sci. Technol. 50(3), 1501-1509.

Zafar, S. (2018). Biofuels from syngas. Available at: https://www.bioenergyconsult.com/biofuels-from-syngas/ (accessed 27/02/2019).

Zafar, S. (2019). Cofiring of biomass. Available at: https://www.bioenergyconsult.com (accessed 21/03/2019).

Zulkafli, N.I., Kopanos, G.M., 2018. A general optimization framework for the design and planning of energy supply chain networks: Techno-economic and environmental analysis. Chem. Eng. Res. Des. 131, 214-233. 